\section{Removable covered self-expanding metal stent for extraction of a large biliary stone in a patient on dual antiplatelet therapy}

A 76-year-old man, who had previously undergone coronary artery bypass grafting but had episodes of myocardial infarction despite dual antiplatelet therapy, was diagnosed with a large common bile duct (CBD) stone that was causing recurrent cholangitis. Based on general agreement among the cardiologists and hematologists, his antiplatelet agents were neither stopped nor replaced with bridging medication. He underwent endoscopic retrograde cholangiopancreatography (ERCP) without biliary sphincterotomy 7 days prior to referral to our unit. His cholangitis was temporarily treated with a straight plastic stent passing alongside the stone; however, within 3 days of the procedure, the stent had migrated distally.

The patient underwent a second ERCP with stent removal at our center. Given the constraints on performing a sphincterotomy, a $10 \times 60-\mathrm{mm}$ fully covered selfexpanding metal stent (SEMS) with anchoring flaps (Hanarostent, M.I. Tech Co., Seoul; South Korea) was deployed across the papilla. An attempt to mobilize the stone with a Dormia basket failed, so the stone was subsequently dragged into the metal stent using a Fogarty balloon ( $\bullet$ Fig. 1 ). The SEMS was easily invaginat-

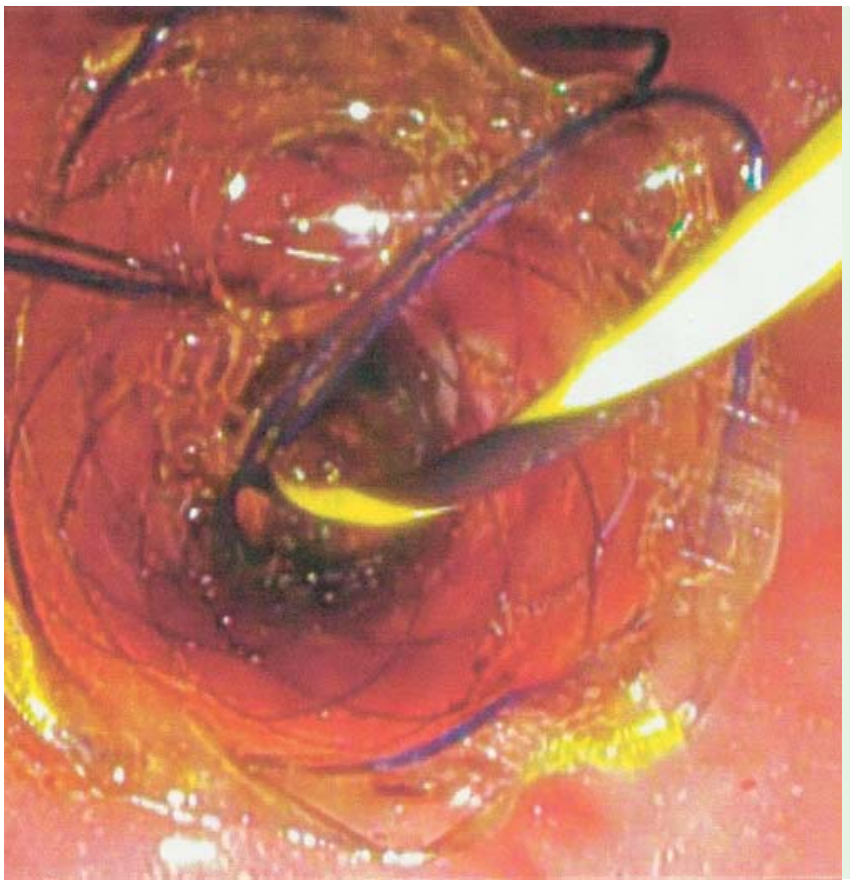

ed from the proximal lasso and was removed with the $\mathrm{CBD}$ stone inside it (० Video 1).

Standard management for the extraction of bile duct stones involves ERCP with biliary sphincterotomy. In patients who are unsuitable for sphincterotomy [1] or young patients wishing to preserve the function of their sphincter of Oddi, endoscopic papillary balloon dilation could be an attractive alternative [2]. However, it is technically a risk factor for post-ERCP pancreatitis [3] and carries a potential risk of papillary bleeding related to the passage of the Dormia basket through the dilated papilla.

SEMSs have been increasingly used to treat benign biliary strictures and bile leaks [4]. Recently, the use of SEMSs has been extended to complex biliary stones as a bridge to repeated attempts at extraction. Cerefice et al. [2], in a series of 36 patients, reported a clinical success rate of $83 \%$, with an $11.1 \%$ stent migration rate.

\section{Video 1}

Fluoroscopic and endoscopic images of the common bile duct stone being successfully extracted by invaginating the self-expanding metal stent (SEMS) using its proximal lasso.

Fig. 1 Endoscopic view showing the stone being dragged into the self-expanding metal stent (SEMS) with a Fogarty balloon catheter.
In this case, the SEMS allowed for gentle extraction of the stone, with only minor trauma to the papilla owing to invagination of the stent. Moreover, the anchoring flaps of the metal stent prevented it migrating distally as the stone was pulled into it with the Fogarty balloon.

In patients receiving dual antiplatelet therapy that cannot be discontinued, the use of SEMSs for stones extraction may be an expensive but safe alternative.

\section{Endoscopy_UCTN_Code_TTT_1AR_2AC}

\section{Competing interests: None}

\section{Enzo Masci, Alessandra Bizzotto, Monica Arena, \\ Benedetto Mangiavillano}

Gastrointestinal Endoscopy Unit, Azienda Ospedaliera San Paolo University Hospital, Milan, Italy

\section{References}

1 Veitch AM, Baglin TP, Gershlick AH et al. Guidelines for the management of anticoagulant and antiplatelet therapy in patients undergoing endoscopic procedures. Gut 2008; 57: 1322 -1329

2 Cerefice M, Sauer B, Javaid $M$ et al. Complex biliary stones: treatment with removable self-expandable metal stents: a new approach (with videos). Gastrointest Endosc 2011; 74: 520-526

3 Liu Y, Su P, Lin S et al. Endoscopic papillary balloon dilatation versus endoscopic sphincterotomy in the treatment for choledocholithiasis: A meta-analysis. J Gastroenterol Hepatol 2012; 27: 464-471

4 Kahaleh M, Behm B, Clarke BW et al. Temporary placement of covered self-expandable metal stents in benign biliary strictures: a new paradigm? Gastrointest Endosc 2008; 67: $446-454$

\section{Bibliography}

Dol http://dx.doi.org/

10.1055/s-0034-1377359

Endoscopy 2014; 46: E342

(c) Georg Thieme Verlag KG

Stuttgart · New York

ISSN 0013-726X

\section{Corresponding author \\ Enzo Masci, MD}

Gastrointestinal Endoscopy Unit

Azienda Ospedaliera San Paolo - University

Hospital

University of Milan

Via A. di Rudinì 8

20142 Milano

Italy

Fax: +39-02-81844647

enzo.masci@ao-sanpaolo.it 